\title{
EL ARTE RUPESTRE EN LA PROVINCIA DE SEGOVIA
}

\author{
M. Rosario Lucas Pellicer
}

En los numerosos trabajos sobre arte rupestre peninsular -paleolitico y postpaleolítico - la provincia de Segovia ha quedado siempre relegada de las investigaciones y existe muy escasa bibliografía al respecto. Sin embargo, día a día van ensanchándose las fronteras de los ciclos artísticos y las limitaciones geográficas se ven rebasadas por nuevos descubrimientos, tanto de pinturas como de grabados.

La existencia de arte en la provincia de Segovia no es una novedad. En 1915, J. Cabré (1) hace mención, por primera vez, de la existencia de pintura en la sierra de Sepúlveda, ampliando la expansión geográfica del arte esquemático peninsular. Esta noticia, sin concretar yacimientos, se ve confirmada por alguna breve referencia, como la del P. J. Carballo (2), a cerca de la existencia de pintura y grabado dentro de los límites de Sepúlveda. Un año después, en 1918, aparece la primera y única monografía de conjunto sobre el arte rupestre del barranco del Duratón entre los términos de Sepúlveda y Carrascal del Río redactada por el marqués de Carralbo (3).

A partir de esta última publicación la provincia de Segovia se incorpora, sin ninguna reserva, al área de expansión de la pintura esquemática y en 1933, el abate $H$. Breuil (4), infatigable investigador del arte

(1) Cabré Aguiló, J.: El arte rupestre en España. «C.I.P.P.» Mem. núm. 14. Madrid, 1915, pág. 90.

(2) Carballo, J.: Nuevos descubrimientos de cuevas de arte rupestre prehistórico en la región de Sepúlveda. "B.R.S.E.H.N.», T. XVII, núm. 9. Madrid, 1917, págs. 544-546.

(3) Cerralbo, Marqués de: El arte rupestre de la región de Duratón. «B.R.A.H.», T. LXXIII. Madrid, 1918, págs. 127-160.

(4) Breuil, H.: Les peintures rupestres schématiques de la Pèninsule Ibèrique. Vol. I (Au nord du Tage). Lagny, 1933, págs. 32-36. 
rupestre español, reseña en el capítulo III, 1, del primer tomo de su monumental obra, los nombres de los yacimientos segovianos, transcribiendo íntegramente, en francés, las descripciones de Carballo y Cerralbo, excluyendo con su competente rigor científico la Cueva de los Siete Altares, tan ponderada por Cerralbo.

Por desgracia, estas publicaciones no tienen apenas eco, a pesar de que, afortunadamente, los hallazgos se van sucediendo y en la actualidad sabemos que las manifestaciones esquemáticas del Duratón no son un hecho aislado, sino que existe, dentro de Segovia, una tradición artística que elige como soporte la roca y que se puede seguir desde el paleolítico hasta la romanización.

Todavía no es mucho lo que se sabe y son grandes las lagunas que podemos hallar. Técnicamente, pintura y grabado aparecen en zonas muy próximas y en épocas que pueden ser coetáneas. El estilo cultiva, dentro de una misma cultura, el esquematismo en sus límites más abstractos o las escenas de dibujo tosco que pretenden ser naturalistas.

En general, y en lo que atañe a arte rupestre, con la introducción de la metalurgia del hierro y con los consiguientes cambios técnicos, económicos y espirituales, impuestos por la nueva civilización, las manifestaciones artísticas sobre la roca, disminuyen progresivamente hasta anular el espíritu que las engendraba en casi la totalidad de la península. En la provincia de Segovia, por el contrario, estas tradiciones parecen pervivir largo tiempo, dentro de un ciclo nuevo y desconocido hasta ahora en España.

Como síntesis y evidencia de lo expuesto se detalla a continuación una serie de lugares (mapa núm. 1) en donde el arte parietal, atribuible a una época determinada, es evidente, mientras que de otros, no comprobados científicamente, sólo tenemos algunas breves referencias que pueden servir de guía a futuras investigaciones.

\section{A) Grabado}

\section{Arte paleolítico}

Contamos únicamente con una sola estación, pero es indudable que no debe de ser un hecho aislado y que son previsibles nuevos descubrimientos cuando la zona se investigue con mayor intensidad. El grabado a que nos referimos se ha localizado en la Cueva de la Griega, en Pe- 
draza (5), junto al arroyo Vadillo, afluente del Cega. Se trata de una cabeza de caballo grabada en la arcilla de la pared. Se fecha en el Auriñaciense de Breuil o fase II de Leroi Gourhan, dentro del Gravetiense o Solutrense antiguo. Esta cabeza de caballo es, hasta el momento, la manifestación rupestre más antigua que se conoce en la provincia.

\section{Arte esquemático}

Al Eneolítico y Edad de Bronce se han atribuido algunos de los grabados de la llamada cueva de Fuente-Dura o de la Vaquera, en Torreiglesias (6) e idéntica cronología relativa se supone para los existentes en la cueva de Prádena (7).

En ambos yacimientos los dibujos son más bien una serie de trazos y líneas confusas de difícil interpretación y estudio, dándose la coincidencia de estar grabados en las paredes de dos cuevas naturales, destinaas a necrópolis, por desgracia saqueadas. En la actualidad ambas estaciones están en curso de excavación y es presumible que los hallazgos y su filiación cultural estén relacianados con las manifestaciones artísticas.

A la misma época que los grabados anteriores debe de pertenecer el signo descubierto en el Covacho del Molino Giriego, en Sepúlveda. En la bibliografía, esta localidad se conoce con el nombre de Cueva, pero personalmente prefiero llamarla covacho para que no haya confusión entre la auténtica cueva explorada por L. Hoyos Sainz en 1908 y este covacho natural que se halla en sus proximidades, en la margen izquierda del río Duratón. Carballo y Cabré (8) lo citan como localidad con pinturas y grabados, pero en nuestros trabajos solamente se ha podido compro-

(5) Almagro Gorbea, M.: La cueva del Niño (Albacete) y la cueva de la Griega (Segovia). Dos yacimientos... «T.P.», Vol. 28. Madrid, 1971, págs. 47-52, láms. VIII-X.

(6) Lemus Chávarri, C., y Alvarez Redondo, J. L.: Grabados eneolíticos de la Cueva de Fuente Dura. "IX C.A.N.". Valladolid, 1965, págs. 162-163.

(7) Cabellos Barreiro, E., y otros: Grabados esquemáticos de la cueva de Prádena. "IX C.A.N.». Valladolid, 1965, págs. 166-174.

Burdiel, I.: Trabajos de reconocimiento de la cueva de Prádena. «N.A.H.». Volumen VI, 1962. Madrid, 1964, págs. 100-102.

Actualmente se efectúan excavaciones en este yacimiento bajo la dirección del profesor V. Argilés, por el que conocemos una serie de fotografías de dichos grabados, muy numerosos y de difícil comprensión.

(8) Carballo, J.: Ob. cit., nota 2.

Cabré Aguiló, J.: Pinturas y grabados rupestres esquemáticos de las provincias de Segovia y Soria. "A.E.A.», núm. 43. Madrid, 1941, págs. 317 y siguientes. 


\section{Arte naturalista}

Enlazando cronológicamente con el arte esquemático y prolongándose hasta la época histórica, Segovia nos ha brindado la sorpresa de un ciclo artístico desconocido hasta ahora en España, con unos motivos que superan la abstracción y el mero esquema, creando bellas escenas naturalistas llenas de impresionismo y vitalidad.

bar la existencia de un grabado representando un gran signo bitriangular en la pared exterior y algunos otros restos, dudosos, en el techo (9).

Estos grabados no aparecen en cuevas ni en abrigos, sino en peñones de esquisto, al aire libre, dentro de la zona de Santa María de Nieva, a lo largo de las márgenes del río Eresma (términos de Armuña, Carbonero, Yanguas, Migueláñez...), con sus focos principales en Ochando (junto al arroyo Balisa) y en Domingo García (alrededores de la ermita de San Isidro) (10).

Aparte de estar ejecutados algunos de ellos con líneas incisas, existe un predominio de dibujos realizados por "puntillado» o "repicoteado» e incluso por líneas discontinuas a base de puntos. Es un arte que todavía no está suficientemente investigado, pero si mis apreciaciones no son erróneas, estos grabados, esquemáticos en sus comienzos, se prolongan hasta alcanzar su esplendor en la primera y segundad edad del hierro, agotándose con la romanización; aunque como es normal en muchos de los lugares rupestres, superposiciones, transformaciones e imitaciones pueden llegar hasta la actualidad. Estos grabados segovianos serían, pues, un fenómeno comparable al del arte rupestre de los Alpes italianos, en Valcamónica y Mont Bego.

\section{B) Pintura}

La expansión geográfica de la pintura rupestre no coincide exactamente con la del grabado y, por el momento, toda la que se conoce debe de incluirse dentro del ciclo esquemático, aunque no falte la abstracción

(9) Lucas Pellicer, María R.: La pintura rupestre esquemática del Barranco det Duratón (Segovia). Tesis doctoral (inédita) presentada en la Universidad Autónoma de Madrid, en 1973.

(10) Gozalo Quintanilla, F.: Arte rupestre en la provincia de Segovia. «Rev. Ejército», núm. 370, noviembre. Madrid, 1970, págs. 5-9.

Lucas, María R.: Grabados rupestres en la comarca de Santa María de Nieva. «Estudios Segovianos», núm. 67. Segovia, 1971, pág. 9.

Idem.: Grabados rupestres en el término de Domingo García (Segovia). "XII C.A.N.\$. Jaén, 1971 (Zaragoza, 1973), págs. 257-266. 
y los dibujos de carácter más naturalista. La mayoría de yacimientos están recogidos en un breve artículo de J. Cabré (11), recopilando la relación que da Cerralbo en su monografía sobre el arte rupestre del río Duratón (12), con algunas ampliaciones e incluyendo también otras noticias que merecería la pena se investigasen. Estas son las siguientes:

Rio Prádena: En las cercanías del Santuario de Nuestra Señora de los Remedios, término municipal de Castroserna de Abajo. A estas mismas pinturas debe de aludir la noticia dada en 1947 por J. Juberías y A. Molinero (13) en la que se dice: «En el barrio del Castillo y en dirección norte existen numerosos abrigos con pinturas en rojo.»

Este barrio del Castillo está formado por un pequeño núcleo de casas deshabitadas, junto al castillo de Castilnovo, en el condado de dicho nombre. En una de las prospecciones por la provincia intenté localizar estos abrigos, bordeando la margen derecha del río San Juan (río Prádena, según Cabré), afluente del Duratón. Entre el kilómetros 3 y 4 de la carretera que desde el castillo se dirige a Castroserna se halla la ermita de Nuestra Señora de los Remedios. En este punto el barranco se hace más prominente y abrupto, formando una acusada curva paralela a uno de los meandros del río. En la risca de la margen derecha, al igual que en la margen izquierda, se distinguen varias cuevas y covachos. Las más destacadas son cueva Oscura, antes de llegar a la ermita, y cueva Grande, casi enfrente mismo de la ermita. La mayoría de estas cuevas son naturales, pero en algunas, como las mencionadas, se nota la mano del hombre que ha transformado las cavidades adaptándolas a sus intenciones (ambas están actualmente destinadas a guardar ganado).

Exploramos cuantas cuevas y covachos parecían más idóneos, pero no se halló ninguna huella de arte o de color a no ser el humo que cubre gran parte de las erosianadas y desgastadas paredes y el rastro de alguna excavación furtiva. A pesar de las indagaciones nadie supo dar razón sobre la posible existencia de pinturas o dibujos, no obstante dada la experiencia de los informadores, es de esperar que futuras prospecciones tengan más éxito que la nuestra ya que, en realidad, la zona está llena de posibilidades (14).

(11) Cabré, J.: Ob. cit., nota 8, págs. 317 y siguientes.

(12) Vide nota 3.

(13) «N.A.H.», Vol. I, 1952. Madrid, 1953, pág. 246. Noticia núm. 510, inventariada como dudosa.

(14) En el Vol. I del "N.A.H.», inventariadas con los números 87 (pág. 187) y 509 (pág. 246), respectivamente, se leen las siguientes noticias: "Cerca de la ermita de Nuestra Señora de los Remedios descubrió D. Justo Juberías una caverna tapiada con grandes piedras que fueron quitadas bajo la dirección del descu- 
Río Caslilla (15): Según Cabré existen pictografías «cerca de Casla, a unostres kilómetros y en el lugar denomanido paseo del Moro». J. Juberías recoge la noticia con alguna ampliación (16), «... hay un abrigo con pinturas azules protegidas con concreciones minerales que revelan su antiguiedad; frente a este abrigo hay una caverna sin explorar».

Río Cega: Según referencias que Cabré no pudo confirmar, se hallan también pinturas en las inmediaciones de Pedraza. Tal vez esta noticia coincida con la dada por J. Juberías al informar de la presencia de un ciervo en un abrigo al aire libre, dentro del término de Pedraza (17), sin especificar técnica ni estilo.

Rio Aguisejo: Sin más especificaciones Cabré alude a la existencia de pinturas entre Languilla y Mazagatos, noticia que J. Juberías amplía (18) diciendo que "hay un abrigo con una figura estilizada y pintada en rojo y restos de cerámica neolítica».

Aparte, Cabré menciona también «pictografías en el alto de la Sierra de Las Cabras, entre Villacadima y Grado" y, al igual que para los sitios mencionados anteriormente, contamos con la duplicidad de la noticia por parte de Juberías, que nos dice que en Grado «existen careonas mal conservadas con vestigios de pinturas en rojo" (19).

Según el propio Cabré, todas las estaciones detalladas pertenecen al ciclo esquemático. En realidad hay que esperar que todas estas breves y confusas referencias se conviertan en otras tantas publicaciones que nos informen más ampliamente. En el mapa adjunto están catalogadas como lugares no comprobados, pero dignos de tener en cuenta, pues por mi parte he de decir que, siguiendo la relación dada por Cerralbo y

bridor, descubriéndose gran número de restos humanos. Apareció gran cantidad de cráneos y un vaso de cerámica con ornamentación interior y exterior y un pendiente de cobre. De los hallazgos se hicieron dos lotes, uno de los cuales fue entregado al Marqués de Cerralbo y otro quedó en poder de D. Alejandro Escudero, propietario de la finca donde tuvo lugar el hallazgo. Queda una memoria de puño y letras de D. J. Juberías con la clasificación de los hallazgos. 1947. J. Juberías y A. Molinero."

«... Entre el barrio donde está el castillo y la ermita existe un abrigo natural que sirvió de paridera, y en su interior, en el suelo, sobre una roca, varias sepulturas de grandes proporciones. 1947...»

(15) Cabré, al igual que Cerralbo, siempre escribe río Castilla (con este nombre está incluido también en el mapa del I.G.C. 1/50.000). En la provincia lo llaman Caslilla y así lo denomina, entre otros, J. Juberías.

(16) "N.A.H.», Vol. I, núm. 506, pág. 245, inventariada como dudosa.

(17) Idem, núm. 528, pág. 248.

(18) Idem, núm. 47, pág. 180.

(19) Idem, núm. 519, pág. 247.

Dentro del término de Villacadima, provincia de Guadalapara, T. Ortego ha publicado el conjunto de Portalón (Vide "Ampurias», Barcelona, 1963, págs. 91-104). 
Cabré, he podido localizar cada uno de los sitios mencionados en el barranco del Duratón, con unos resultados más que satisfactorios como se verá más adelante, aunque las transformaciones actuales y la erosión y otras vicisitudes nos hayan privado de la totalidad.

Aparte, a estos sitios dudosos o no documentados gráficamente, hemos de añadir la noticia de la existencia de un abrigo con restos de pinturas rojas, junto a «inscripciones ibéricas y muchos instrumentos paleolíticos y neolíticos» (20), a un kilómetro del pueblo de Moral de Hornuez.

Igualmente hay que incluir aquí la presencia de pinturas en la cueva de Prádena, a la que ya se ha aludido en el apartado de grabado (21). Ignoramos edad y estilo, pero posiblemente pertenezcan a la misma cultura que los grabados y los enterramientos, aunque sin más datos es aventurada cualquier filiación cultural, e incluso parece que su existencia está en entredicho a pesar de que la referencia de I. Burdiel parece no ofrecer dudas.

Finalmente, el conjunto más espectacular de arte rupestre esquemático lo ofrece el barranco del Duratón, con 27 localidades diferentes, todas ellas con pintura, frente a un solo sitio con grabado, el covacho del Molino, al que ya se ha hecho alusión.

Este conjunto se extiende a lo largo de unos 33 kilómetros, desde Sepúlveda hasta la presa del Burguillo (Burgomillodo), en el término de Carrascal del Río, y el estudio de sus manifestaciones rupestres ha sido el tema de mi tesis doctoral. Como resultado hay que señalar que, de todos los lugares mencionados en la bibliografía, cuevas Lóbregas y cueva Labrada o cueva de la Fuente del Caldero (ambas citadas por Carballo y Cabré) deben de desecharse, en mi opinión, de los repertorios de arte rupestre. La primera porque, aparte de que no hallamos ni grabados ni pinturas, su aspecto no parece tener relación directa con el arte prehistórico. La segunda porque, sin lugar a dudas, su contenido artístico es moderno. Como más evidencia hay que decir que si el arte rupestre de la zona se sitúa siempre en cavidades o abrigos naturales, cuevas Lóbregas es semiartifical y cueva Labrada, como su nombre indica, completamente artificial. La relación actual, según mis investigaciones, y

(20) «N.A.H.», Vol. I. Madrid, 1953, núm. 238, pág. 207.

(21) Burdiel, I.: Ob. cit., núm. 7, en donde se lee: «En una nueva galería en la parte alta, sobre una de las rocas, encontramos unas pinturas hechas con pintura negra; sólo una se puede identificar: aprovechando una oquedad en dicha piedra se ha querido representar la cabeza de un équido,» 
con las salvedades que se indican, siguiendo un orden de Este a Oeste, a partir de Sepúlveda, es decir, aguas abajo del río Duratón, es la siguiente:

TÉrMino dE SEPÚlvedA

Abrigo del Molino: En las inmediaciones del Molino Giriego. Margen derecha del río. Indicios de pintura. Inédita.

Peña Higuera: Margen izquierda: Sólo contiene tres figuras pintadas en rojo. Inédita.

Cueva de la Huelga: Margen derecha. Contiene pinturas modernas y un signo auténtico. Inédita.

TÉRMino de CASTRILlo (margen derecha del río)

Abrigo 1 del Cabrón: Contiene un grupo de cuatro motivos y otros restos de color. Inédito.

Conjunto 2 del Cabrón: Citado por Cerralbo. Cabré lo llama cueva del Cabrón. Este conjunto contiene dos abrigos diferentes, uno con puntuaciones y otro con dos figuras humanas inéditas.

En este término se halla otro abrigo mencionado por Cerralbo. Según nuestros trabajos se trata de unas pinturas modernas que representan una serie de cruces.

TÉRMINO DE VILLASECA (22) (margen derecha)

Entraderas $A$ y $B$ : Se trata de dos abrigos muy próximos entre sí, cuyas pinturas describe Cerralbo; en la actualidad ambos abrigos han sido convertidos en aprisco y las pinturas son irreconocibles.

Solapa de los Angostillos: Mencionada por Cerralbo y Cabré. Contiene unos siete pequeños grupos de pinturas.

Solapa del Juego de la Chita: Según Cerralbo sus pinturas son mo-

(22) En la relación de Cerralbo y Cabré los nombres no coinciden totalmente (es más exacta la de Cabré). Personalmente he procurado recoger la denominación local y así desecho la palabra "solapo" usada por Cerralbo y la hago femenina de acuerdo con Cabré, es decir, "solapa», vocablo con el que los naturales designan a los abrigos abiertos, largos y relativamente estrechos. 
dernas. Cabré no hace ninguna observación a este respecto. Se han podido comprobar que las pinturas pertenecen a dos épocas. Contiene en total unos seis grupos.

Solapa de la Molinilla: Conocida también con el nombre de Solapa de la Pinta. Interesante conjunto, con unos dieciséis grupos, algunos muy bien conservados. Citada por Cerralbo y Cabré.

Cueva de la Nogaleda: Cueva natural probablemente destinada a necrópolis. Hubo al menos tres grupos de pinturas, actualmente uno de ellos está magníficamente conservado. En la relación de arte rupestre sólo la cita Cabre, aunque Cerralbo hace alusión a ella en otros escritos (23).

Solapa de Valdegarcía: Vestigios de pinturas. Inédita.

Cueva de la Llave: Cueva natural que no hemos explorado en su totalidad. Existe un manchón pintado en la entrada. Cerralbo la incluye entre los yacimientos prehistóricos, pero la excluye de los sitios con pinturas.

Solapa del Aguila: Es, sin duda, el mejor abrigo del conjunto. Contiene unos 30 grupos de pinturas con numerosos motivos. Citada por Cerralbo y Cabré. Un pequeño avance de su contenido se publicó en 1971 (24).

TÉrmino del Burguillo, JuRisdicción dE CarRascal DE ARriba (margen derecha).

Solapa del Polvián: Hoy sumergida en el agua del pantano. Cabré la llama Solapa del Cabo Abajo del Polvorín (sin duda confunde Polvorín con Polvián). Cerralbo menciona dos abrigos después del Canto del Común, que yo identifico con esta solapa y con la siguiente.

Solapa de la Suma: Localidad en idénticas circunstancias que la anterior. Cabré la denomina Solapa del Mirón. Cerralbo menciona el paraje de la Sima del Mirón, aunque omite la existencia de pinturas.

Abrigo de Santa Engracia o del Batán: Restos de pintura. Inédito.

Abrigo de San Frutos: Vestigios de color. Inédito.

Bugerones de San Frutos o Parajes del Santero: Se trata de dos covachos naturales en donde existen cinco grupos de pintura (alguno du-

(23) Gómez Moreno, M.: Misceláneas, I., Madrid, 1949, pág. 101.

(24) Lucas, María R.: Pinturas rupestres del Solapo del Aguila... «T.P.», número 28. Madrid, 1971, págs. 119-153. 
doso). Mencionados por Cerralbo y también por Cabré que da un tercer nombre: Escalera del Diablo.

Término de Carrascal de ARriba (margen izquierda)

Carrascal 1 ó La Pez (25): Rincón abrigado, próximo a la gran solapa de La Pez, hoy sumergida. Escasas pinturas.

Carrascal 2 ó Abrigo del Medio: Contiene unos siete grupos de pinturas.

Carrascal 3 ó Abrigo Grande: Se puede separar su contenido en unos doce grupos de pintura, alguno muy interesante.

Abrigo 1 de Las Rozas (26) o Abrigo de La Tumba: Sólo conserva un grupo. Inédito.

Abrigos 2, 3 y 4 de Las Rozas: Solapas naturales, muy próximas, de grandes dimensiones. El número 2 con un único grupo de pinturas, muy perdidas. El número 3 sólo contiene algunos signos aislados. En el número 4 se aprecian claramente dos agrupaciones. Todos inéditos.

Como se deduce de los breves datos reseñados, el conjunto del Duratón es sumamente interesante por la densidad de contenido, aunque, por desgracia, para los lugares de Las Entraderas su contenido artístico sólo se podría estudiar si se realizase una limpieza exhaustiva de las paredes y la fortuna acompañase en la conservación de los dibujos, hoy completamente enmascarados por el humo. La descripción de Cerralbo es básica, por el momento, para adivinar lo que pudo existir. Otras dos solapas (del Polvián y de la Suma) quedan sumergidas bajo el nivel de las aguas del pantano. Su reconocimiento sólo sería posible si el cauce volviera a su nivel primitivo. De estas localidades no tenemos descripción alguna y sólo disponemos de su nombre. For otra parte, los abrigos del Molino, Valdegarcía, Santa Engracia y San Frutos, así como la cueva de La Llave y alguno del paraje de Las Rozas, apenas si conservan algunos indicios de manchas de color. Si se incluyen en la relación es porque juzgo importante conocer la densidad del núcleo artístico y las determinantes que han podido influir en ia elección del lugar.

Igualmente se puede deducir que la estación más importante es la

(25) Los tres abrigos denominados Carrascal 1 a 3 creemos que coinciden con las citas de Cerralbo y Cabré en las que aluden a tres sitios diferentes en la margen izquierda del río, en las inmediaciones del Batán.

(26) Todos estos abrigos están dentro del paraje de las Rozas, en frente de la Meseta de San Frutos. 
de la Solapa del Aguila, seguida por la de la Molinilla y el Abrigo Grande de Carrascal. La cueva de la Nogaleda, La Chita, Carrascal del Medio y Los Angostillos siguen en importancia. Los restantes sitios conservan algunos signos o figuras y su interés radica en formar parte de todo el conjunto.

También se puede comprobar en la suscinta relación que la mayor parte de las estaciones aparecen en la margen derecha, dentro del término de Villaseca, mientras que hacia la desembocadura del barranco (presa del pantano, en los alrededores de la Meseta de San Frutos) se extienden en ambas márgenes, con una densidad mayor en la izquierda.

Ignoro si la ausencia de arte rupestre entre Sepúlveda y Carrascal, dentro de la margen izquierda (desde Peña Higuera a La Pez) se debe a una selección (la margen derecha es más abrupta que la izquierda) o simplemente al hecho de que tanto nuestros predecesores como yo misma, hemos intensificado más la exploración en la margen derecha.

Otras características dignas de mención son que, aparte del contraste estilístico y temático entre unas y otras estaciones $\mathrm{y}$, aunque el color rojo oscuro sea el predominane, existen también otras coloraciones como la roja más viva y el bicromismo de algunos grupos con la aparición del color negro, como, por ejemplo en Carrascal del Medio, color mencionado ya por Cerralbo en uno de los abrigos de las Entraderas y que también se puede comprobar en algunos otros sitios.

En mi opinión, todo este conjunto que debió tener una larga duración, debe de situarse, cronológicamente, en la segunda mitad del segundo milenio, prolongándose hasta bien entrado el primero, con una temática sugestiva que nos plantea el viejo problema de relaciones, influencias o contactos con otros conjuntos peninsulares, iniciado ya con los comentarios de $\mathrm{H}$. Breuil (27) al transcribir los datos aportados por Cerralbo.

(27) Vide nota 4. El Abate Breuil concluye las descripciones diciendo que, ciertamente, "existe en la Sierra de Sepúlveda y en Castilla la Vieja un grupo de pinturas rupestres estrechamente emparentadas con los conjuntos más modernos de la Península Ibérica, y que muchos de los signos que aparecen en ellas son comunes a las Batuecas, Peña Tú, Pala Pinta e incluso a otros núcleos más orientales». Hay que decir que estos paralelos basados en la descripción de Cerralbo son bastante exactos. A conclusión parecida llegó Cabré en su artículo citado en la nota número 8.

En 1969. P. Acosta (La pintura rupestre esquemática en España, Salamanca, 1968) se hace eco de la bibliografía mencionada y sitúa en sus mapas, de acuerdo con las descripciones de Breuil y Cerralbo, algunos de los motivos existentes en en los abrigos del Barranco del Duratón, en especial los de la Solapa del Aguila. Tanto esta autora, como otros eruditos en arte rupestre, aluden a este conjunto, como obra cronológicamente tardía, con un arte paralelo al de las Batuecas. Espero 
Finalmente, y a modo de colofón, como una pervivencia más de las tradiciones rupestres segovianas, de tan honda raíz, se puede mencionar a la famosa cueva de Siete Altares (Villaseca), en donde los monjes visigodos nos dejaron testimonio de su arquitectura y ornamentación al esculpir y labrar las rocas, repasando con color rojo los motivos decorativos de las hornacinas abiertas en la angosta caverna que se asoma a la ribera derecha de las aguas del Duratón.

De la síntesis global del arte rupestre de Segovia, al observar su distribución en el mapa de la provincia, se infiere la existencia de dos zonas bien diferenciadas, una la oriental en torno al Duratón y su confluencia con los ríos Serrano y San Juan, prolongándose hasta el Cega. En este área se centra el gran núcleo de pintura esquemática, así como el grabado paleolítico de Pedraza y los grabados de la cueva de Prádena, inéditos en su conjunto total y en donde se ha apuntado la posibilidad de la existencia de pintura.

Otra zona, la más occidental, abarca los alrededores de Santa María de Nieva, junto al Eresma, en donde el arte del grabado es único y nos sorprende por la novedad y contraste con el grupo anterior en donde predomina la técnica de la pintura, con un estilo cronológicamente mucho más antiguo.

Torreiglesias queda como un punto aislado entre los dos núcleos artísticos. Por otra parte hacia el NE. se aislan de la primera área los yacimientos, no comprobados, de Moral de Hornuez, Languilla y Grado, que se unen ya al arte de la provincia de Guadalajara, con la localidad de Villacadima, publicada por T. Ortego (28), así como a el arte rupestre soriano, tan difundido por dicho autor.

Vista, pues, la dualidad de ambas zonas geográficas y los puntos aislados entre los dos núcleos, marcando una posible relación entre ellos y entre el arte de las provincia de Soria y Guadalajara, nada extrañaría que una búsqueda más intensa de yacimientos nos revelara nuevos lugares artísticos, con la esperanza de ampliar los yacimientos paleolíticos ya que en la relación adjunta el grabado de Pedraza es un hecho aislado.

Segovia es una provincia nada desdeñable en los estudios de arte rupestre, con un futuro lleno de promesas para aquellos investigadores que se interesen por esta materia. Hay que comprobar los lugares reseñados, desechar errores si los hay, buscar las relaciones posibles, la

que la publicación de mi tesis doctoral aporte toda la documentación gráfica obtenida, para ampliar en su justa medida el arte esquemático peninsular y valorar científicamente este interesante conjunto. 
evolución estilística..., así como analizar el por qué de la preferencia por una u otra técnica (grabado y pintura) y su exacta filiación cronológica.

Indispensables serán las comprobaciones y la búsqueda de nuevos lugares artísticos, aunque no hay que olvidar la importancia de localizar nuevos yacimientos arqueológicos en relación con las manifestaciones artísticas. Los grabados de la cueva de la Vaquera y de la cueva de Prádena, tan vinculados con los yacimientos arqueológicos respectivos, pueden abrir un nuevo capítulo en el estudio del arte rupestre hispánico. 


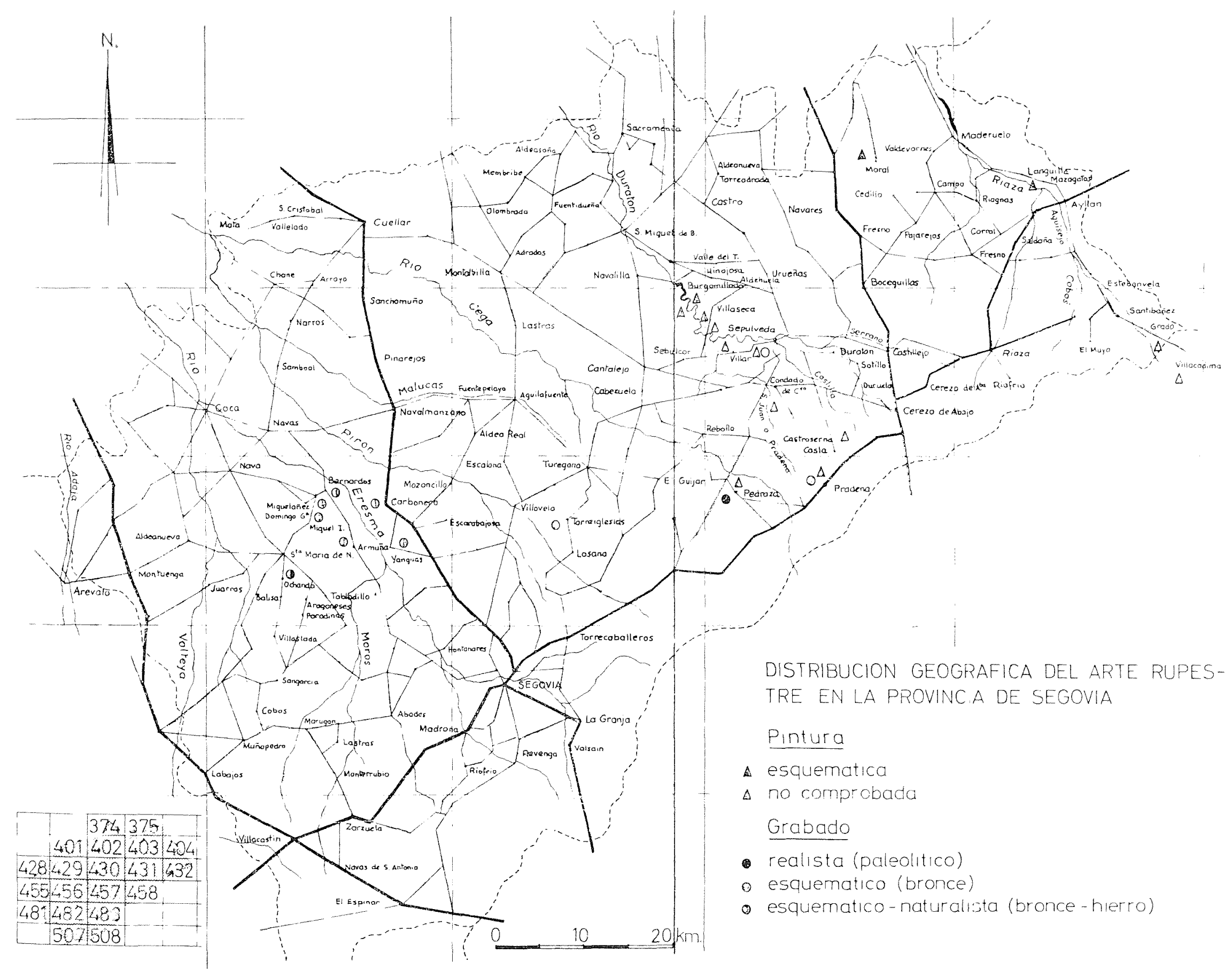

